J. A. McClung • N. Naseer $\cdot$ M. Saleem - G. P. Rossi •

M. B. Weiss · N. G. Abraham - A. Kappas

\title{
Reply to comment on: McClung JA, Naseer N, Saleem M et al. (2005) Circulating endothelial cells are elevated in patients with type 2 diabetes mellitus independently of $\mathrm{HbA}_{1} \mathrm{C}$. Diabetologia 48:345-350
}

Received: 11 August 2005 / Accepted: 15 August 2005 / Published online: 25 October 2005

(C) Springer-Verlag 2005

To the Editor: We appreciate the comments of A. Thanopoulou and colleagues [1]. They correctly observe that the number of control subjects was small in relation to the number of diabetic subjects. This was possibly as a result of the very small standard error associated with circulating endothelial cell (CEC) measurement in the control subjects, hence yielding a statistically very significant difference $(p<0.001)$ between the control and experimental populations. As an incidental observation, the mean number of CEC in our control population [2] is very similar to that previously observed [3].

A. Thanopoulou and colleagues also rightly observe that $60 \%$ of the diabetic subjects were diagnosed with hypertension, as compared with only $10 \%$ of the control subjects. Similarly, $44 \%$ of the diabetic subjects were taking statins for hyperlipidaemia, as compared with none of the control population. Unfortunately, type 2 diabetes mellitus is very frequently associated with these complications as part of the metabolic syndrome, making it extremely difficult to exclude them. Only two diabetic subjects had neither of the above diagnoses and their number of CEC was 64 and 55, respectively. Additional investigations designed so as to

J. A. McClung $\cdot$ N. Naseer $\cdot$ M. Saleem $\cdot$ M. B. Weiss

Cardiology Division and Medicine,

New York Medical College,

Valhalla, NY, USA

G. P. Rossi

University Hospital of Padua,

Padua, Italy

N. G. Abraham $(\bowtie)$

Department of Pharmacology and Medicine,

New York Medical College,

Valhalla, NY 10595, USA

e-mail: Nader Abraham@NYMC.EDU

Tel.: +1-914-5944132

Fax: +1-914-5944119

N. G. Abraham · A. Kappas

The Rockefeller University,

New York, NY, USA exclude hypertensive and hyperlipidaemic patients would help to clarify this issue. In animal models of type 2 diabetes, we showed that increases in CEC are not only dependent on hyperglycaemia alone but also on insulin levels.

As regards the concern that the absence of a correlation between $\mathrm{HbA}_{1} \mathrm{c}$ and the number of CEC makes it difficult to associate CEC with the vascular complications of diabetes, we currently hypothesise that vascular damage in type 2 diabetes may be more strongly related to insulin resistance than to hyperglycaemia in itself. This is suggested by the trend identified between CEC levels and BMI. Further research in this population will serve to identify whether or not this trend is, in fact, statistically significant and whether or not it is associated with measures of insulin levels, such as $\mathrm{C}$ peptide.

\section{References}

1. Thanopoulou A, Karamanos B, Archimandritis A (2005) Comment to: McClung JA, Naseer N, Saleem M et al. (2005) Circulating endothelial cells are elevated in patients with type 2 diabetes mellitus independently of $\mathrm{HbA}_{1} \mathrm{c}$. Diabetologia 48:000-000 DOI: 10.1007/s00125-004-1647-5

2. McClung JA, Naseer N, Saleem M et al. (2005) Circulating endothelial cells are elevated in patients with type 2 diabetes mellitus independently of $\mathrm{HbA}_{1} \mathrm{c}$. Diabetologia 48:345-350

3. Woywodt A, Streiber F, de Groot K, Regelsberger H, Haller H, Haubitz M (2003) Circulating endothelial cells as markers for ANCA-associated small-vessel vasculitis. Lancet 361:206-210 